\title{
Types and Tactics of Questioning used by a Native-speaker Teacher in Teaching Active and Passive Classes
}

\section{Emilia Suryani Gunawan}

English Department, Faculty of Languages and Literature, Petra Christian University, Siwalankerto 121-131, Surabaya 60236, East java, INDONESIA

E-mail: emiliasuryanigunawan27@gmail.com

\begin{abstract}
The purposes of this study are to find out what are the types of questions and questioning tactics used by native speaker teacher of English in teaching passive and active classes and what are the tactics of questioning used related to each type of questions being used by the native speaker teacher of English in passive and active Speaking 1 classes. The theories are taken from Wragg and Brown (2001). According to Wragg and Brown (2001) there are 3 types of questioning which are conceptual question, empirical question, and value question. Other than that, there are 7 tactics of questioning which are structuring, pitching and putting clearly, directing and distributing, pausing and pacing, prompting and probing, listening to replies and responding, and sequencing (Wrag \& Brown, 2001). The findings showed that the teacher of Speaking 1 used the same types of questions which are conceptual and empirical types of questions. Furthermore, tactics of questioning that the teacher used are different in active and passive classes. The teacher mostly used empirical types of questioning for both passive and active classes. In teaching passive class, the teachers mostly asked sequencing of questions as the tactics of questioning. On the other hand, in active class, the teacher mostly asked prompting and probing as the tactics of questioning.
\end{abstract}

Keywords: types of questions, tactics of questioning, native speaker teacher of English

\section{INTRODUCTION}

In language classroom questioning, is defined as a communication pattern between teachers and students (Ma, 2008). "The patterns of classroom communication ultimately determine students' participation in classroom activities by using the language, and the opportunities and efficiency of the target language acquisition" (Ma, 2008, p. 92). In other words, questioning can help the students to participate and to stay focus on the teaching and learning activities inside the classroom. There are many reasons for teachers to ask questions. According to Turney, et al, (1973, cited in Wragg \& Brown, 2001) list twelve functions of questioning but the most common ones are to "check knowledge and understanding, to diagnosing students difficulties, and to recall of facts". Teachers can check their students understanding by seeing student's ability to answer and explain the answer. As stated by Arslan "Questioning has been and is a dominant method of instruction in the classroom. Some say questioning is, in fact, the most important teaching technique in use today. Research indicates that almost $40 \%$ of classroom time is spent in a question-response mode" (2006, p. 82). Thus, questioning is the most common teaching method and cannot be separated from the learning process.

In asking questions, teacher uses different types of questions according to its function and purpose. The types are conceptual questions, empirical questions, and value questions (Wragg \& Brown, 2001). The aim of asking the right types of questions at the right situation is to make the students engage more on the learning process. Furthermore, it is important to ask question with the right tactic, which will make the student become more active in participating classroom activity and learning process. The tactics are structuring, pitching and putting clearly, directing and distributing, pausing and pacing, prompting and probing, listening to replies and responding, and sequencing (Wragg \& Brown, 2001). Types of questions and tactics of questioning proposed by Wragg and Brown (2001) will preserve as the main theory of this study.

In this present study, the writer solely focuses on questions types and tactics of questioning used by native speaker teacher of English teacher in teaching Speaking 1 passive and active classes. The writer conducts an observation at English Department (ED) of Petra Christian University (PCU). Native speaker teacher of English is suitable for this present study because native speaker teacher is closely related to teach speaking; some might say that the best teacher to teach speaking is native speaker teacher. 
Speaking 1 is taught by a native-speaker teacher who has 4 years of teaching experience. The native-speaker teacher is an American who was born in America then works as a teacher in Indonesia. the native speaker teacher is considered as a native-speaker teacher because according to Medgyes (2001, p30), "a native speaker of English is traditionally defined as someone who speaks English as his or her native language, also called mother tongue, first language, or L1." Other than that, the native-speaker teacher is considered as a native speaker because he was born in America and according to Davies (2003), "native speaker is for a start one who can lay claim to being a speaker of a language by place or country of birth or adoption" (p.viii). He is a native-speaker teacher of English who graduates from Union University and has 4 years of teaching experience. Furthermore native speaker teacher of English is suitable for this present study because native speaker teacher is closely related to teach speaking; some might say that the best teacher to teach speaking is native speaker teacher. The reasons why native speaker teacher of English is the best teacher are because as cited by Kayaoglu in his journal (2000), native speaker teacher of English is speaks better English, uses real language, and uses English more confidently. Other than that, native speaker teacher of English focuses on fluency, meaning, language in use, and oral skill.

The main theories of this study are types of questions and tactics of questioning taken from Wragg \& Brown (2001). According to Wragg \& Brown there are three types of questions. The first type is Conceptual Questions is a type of question that concerns with eliciting ideas, definitions and reasoning in the subject being studied (p.16). The second type of question is Empirical Questions is a According to Wragg and Brown, empirical questions are "questions that involve observation, recall of facts and possible experimentation" (p.17). The last type is Value Question classified as questions that are "concerned with morals, social concerns such as poverty, health issues such as smoking, and environmental issues such as pollution" (p.18-19). Moreover, according to Wragg \& Brown (2001) there are seven tactics of questioning. The first tactic is structuring (signposting) is a tactic that "consists of providing signposts for the sequence of questions and the topic. The structuring may be a brief exposition of the topic, are view of a series of questions and explanations based on a previous lesson or a statement of objectives (p.29). The second tactic is pitching and putting clearly, 'pitching' is "estimating the right intellectual level of the people you are teaching, so that you neither bewilder nor patronize them" (p. 29). Furthermore, Wragg and Brown (2001) say, 'putting' is "phrasing the question by using words and phrases that are appropriate to the individual pupil or group" (p. 30). The third tactic is Directing and Distributing is a tactic where the teacher directs the question by using "name, gesture, head movement or facial expression" (p. 31). The fourth tactic is Pausing and Pacing is "pausing briefly after a question and after an answer encourages more pupils to answer, more of the pupils to provide longer answers and more questions from pupils" (p. 32). The fifth tactic is Prompts and Probes is a tactic that works as follow-up questions when the first answers are inadequate, or inappropriate" (p. 33). The sixth tactic is Listening to Replies classified as "Our capacity to listen diminishes with anxiety, so it is not surprising that sometimes teachers may not listen carefully to the responses of pupils and so do not respond appropriately to their answer and comments" (2001, p. 34). The last tactic is Sequencing of Questions is "is often the responding moves of the teacher in between questions" (p. 36). Wragg and Brown classified sequences of questions into 7 sequences, extending and lifting, the circular path, from narrow to broad, from broad to narrow, a path of questions all the same type, a backbone of questions and the random walk (p.36).

This study is done to find out two answers: (1) What are the types of questions and questioning tactics used by native speaker teacher of English in teaching passive and active classes? and (2) What are the tactics of questioning used related to each type of questions being used by the native speaker teacher of English in passive and active classes?

\section{METHOD}

The approach that was used by the writer is qualitative approach. According to Parkinson and Drislane (2011, p2), "Qualitative research is research using methods such as participant observation or case studies which result in a narrative, descriptive account of a setting or practice." Therefore, this study is considered as a qualitative research because of two reasons: (1) the writer used participant observation as the data collection method and (2) the result of this study is in narration. 
The source of data of this present study is whole class interactions and the data of this study is teacher's questions that were asked by Speaking 1 teacher in teaching passive and active classes. The writer omitted teacher's questions that were not related to the topic. First, the writer needed to decide the passive and active class by using observation. The writer observed all 4 four classes. In order to find out which classes were passive and active, on the first observation the writer counted the teacher's questions that were related to the topic and how many students answered or responded to each question.

In order to obtain the data, the writer applied some steps. The writer's first step was to research some information about the teacher, classes and their schedules. Second, the writer met the native-speaker teacher who taught the classes to ask permission to observe the second and third meetings on August 30, 2018 and September 6, 2018. The topic of the second and third meetings were "Giving Directions" and "Could I Please Talk to Helen?." The writer used classroom observation as the data collection method. Hence, the writer used observation protocol

After observing all classes, the writer had a discussion with the teacher to discuss to discuss which class was passive and which class is active. After some discussion, the writer and the teacher agreed that $\mathrm{B}$ was the passive class and $\mathrm{C}$ class was the active class, and these two classes were best to be observed. The $\mathrm{B}$ class was considered as the passive class because the students are mostly silent in class and $\mathrm{C}$ class was considered as active class because the students were actively engaged in classroom activities.

On the day of the observation, the writer played role as a non-participant observer who sat at the back of the class and recorded the data. Observation tools that the writer used are observation protocol, audio recording, and video recording. The writer did not engage or have direct involvement with the activity or the students (Creswell, 2001). After collecting all the data, the writer transcribed all recording by using verbatim transcription with the help of observation protocol. Verbatim transcription "involves typing everything you hear (in an audio recording) and/or see (in a video recording). This includes representing all utterances made by all participants without changing nonstandard language usage (e.g. 'he don't care about me') or dialect (e.g. Doric Scots usage of 'fit like?' for 'how are you?') and without skipping over repetitions ('and-, and-'), false starts ('uh-, well, I mean') and backchannels ('mm-hmm')" (Paulus, Lester, \& Dempster, 2015. p.97).

In order to analyze the data of this study, the writer transcribed all the data. After the writer finished transcribing all the recorded data, the writer highlighted the questions that could be categorized into its types of questions and tactics of questioning. After that, the writer wrote down her analysis in the notes column. Then, the writer counted the types and tactics that were used by the teacher for each class. The total was based on frequency of occurrence.

\section{FINDINGS AND DISCUSSIONS}

In general, the writer found out that native speaker teacher of English used two types of questions the most, namely empirical questions and conceptual questions for both classes. In teaching passive and active classes, the teacher did not used any value questions because the focus of the lesson was on the concept of giving directions, taking and leaving notes, and pronunciation. The focus of the meetings did not have any relation to moral, social issues, or believes, because of that reason; the teacher did not ask any value question. Out of three types, the teacher used empirical questions the most. The teacher approximately asked 299 empirical questions for both classes. The example of the teacher asking empirical question is provided below.

(1.1.29) T: alright, thank you, have a sit, so you can see it from the picture, two men are talking, looks like they might be in a.... hotel room maybe. This man has just changed the shirt because of?

(S1.1.40) S: he spilled coffee on it

(1.1.30) $\mathrm{T}$ : he spilled coffee on his shirt, have you ever spilled coffee on your shirt?

(S1.1.41) S: no

(S1.1.42) S: never

(S1.1.43) S: I did

(1.1.31) T: oh yeah?

(S1.1.44) S: today 


\section{(1.1.32) T: what did you do? you change your shirt? Or you walk around with} stained shirt?

(S1.1.45) S: I change my shirt

Example above is the example of teacher asking empirical question. The teacher asked a set of question. His first question is "This man has just changed the shirt because of?" The teacher aimed to help the student to observe what happened in the picture provided by the book. Then the teacher would like to link it to the student's own experience by asking the second question "have you ever spilled coffee on your shirt?" The second question aimed to help the student to recall facts from his or her own experience. The last question is "what did you do? You change your shirt? Or you walk around with stained shirt?" The teacher aimed to help the student to recall facts whether the students have spilled something on their clothes and what they did at the time.

Furthermore, the teacher used different tactics of questioning in teaching both classes. In teaching passive class, the teacher frequently used sequencing (63), probing and probing (53), pausing and pacing (19). Moreover, in active class, the writer found out that the teacher frequently used tactics are prompting and probing (63), sequencing (45), pausing and pacing (13). The examples and explanation are provided below:

The example of Sequencing

(1.2.145) T: so you are not from Surabaya? Where are you from?

(S1.2.164) S: Situbondo

(1.2.146) T: Situbondo is East Java, right? But is it far away from Surabaya?

(1.2.165) S: not really

(1.2.147) T: is it closer to Banyuwangi or Jember?

(S1.2.166) S: it is close to Bondowoso

Example above is the example of a backbone of questions with relevant digressions. $\mathrm{T}$ used a backbone of questions with relevant digressions when $T$ asked where the student came from and then linked it to the topic of discussion which was about the things that the student wanted to buy for his or her friend. However, the student was not from Surabaya and was not familiar with Surabaya, so the teacher modified the questions' situation based on the students' hometown. T asked question that was closely related to the topic discussed and he asked this question when they had an individual conversation.

The Example of Prompting and Probing

(1.1.73) T: still new, you should know, you have been here for months now, you should know. We are done talking about the library, what else?... What

(S1.1.98) S: W building other famous place that you know about?... which one?

(S1.1.99) S: Starbuck

(S1.1.100) S: P canteen

(1.1.74) T: what else?

(S1.1.101) S: student service?

(1.1.75) T: student service, one more... how about Starbucks? Okay, now take turns with your partner, where it is located and what it looks like, alright? Have you been to the library yet?

(S1.1.102) S: yes

Example above is the example of prompting and probing question. The teacher asked about rooms or offices that the Petra university students should know as they are important for the students. When the teacher asked his first question "What other famous place that you know about?... which one?", there were some students who answered him. However, the teacher wanted the students to give more location as the location given by the student was inadequate. Therefore, the teacher asked the second question "what else?", in order to get more answers from the students.

The Example of Pausing and Pacing

(1.1.93) T: okay, what? It is the tallest building in the campus right? Oh! Yeah yeah I know that, so you go to the $\mathrm{W}$ building and then what? .....

(S1.1.119) S: take the lift 
(1.1.94) T: take the lift to the...

(S1.1.120) S: fourth floor

Example above shows that the teacher was pausing by giving a couple of second silent to give time for the student to think the answer. The pause is marked by the sign of (...).

The writer also found out that tactics of questioning related to each type of question used by the native speaker teacher of English is different for each class. However, the teacher mostly used prompting and probing in asking empirical question for both classes. Other than that, as for conceptual question, the teacher mostly used prompting and probing tactics in passive class and pitching and putting clearly in active class.

In passive class, for conceptual question, the teacher used prompting and probing for four times, pausing and pacing for three times, directing and distributing for three times, and pitching, putting clearly for three times, and listening to replies for once. On the other hand, for the empirical question, the teacher used sequencing for 63 times, prompting and probing for 51 times, pausing and pacing for 16 times, listening to replies for 15 times, directing and distributing for 15 times. In asking conceptual question, the teacher did not use any structuring and sequencing. Other than that, in asking empirical question, the teacher did not use any pitching and putting clearly. The result showed that the tactics of questioning that the teacher used the most when asking conceptual question is prompting and probing and the teacher used sequencing the most in asking empirical question. The table above shows in asking empirical and conceptual question, the teacher used prompting and probing the most. The examples and explanations are provided below.

\section{Conceptual questions}

- Pitching and putting clearly:

(S1.1.110) S: the auditorium is located in the entrance hall, from here you need to go down stairs and then follow the corridor to the right and then there is a stairs and go left and go straight, there is an open place in the right building and then enter the building and there is a some short of

(1.1.86) T: what is this? (asking with up and down hand gesture)

(S1.1.111) S: spiral stairs beside the student service

(1.1.87) T: it is called a ramp, so you go up the ramp....

Example above is the example of the teacher asking conceptual question by using pitching and putting clearly tactic. This question is conceptual question because the teacher wanted to give new concept that stairs and ramp was two different things. As the question has connection to language register.

- Directing and distributing:

(1.2.66) T: let's see you two (pointing at two students), a different one

(S1.2.73) S: hello, could I please speak to Aretta?

(S1.2.74) S: speaking

(S1.2.74) S: are you available? Let's watch movie with me

(S1.2.75) S: what movie? When?

(S1.2.76) S: just let's watch movie together with me

(S1.2.77) S: no I don't want to if I don't know where and when. Bye

(all student laughing and find it funny)

(1.2.67) T: okay, what else do you want to know besides the place? (making eye contact with the student)

(S1.2.78) S: what movie

Example above is the example of the teacher asking conceptual question by using directing and distributing tactic. The question is asked to help the student to form relevant concept of what are the questions that the student needed to ask to when the student was invited by someone. The teacher directed the question to one student by making eye contact with the student.

- Pausing and pacing:

(1.1.36) $\mathrm{T}$ : it is a street name. Okay, it is a little bit strange but this is how we say $i$, if you are going to refer a street, you will say on, alright?

\section{Petra campus is....}

(S1.1.49) S: on Siwalankerto

Example above is the example of the teacher asking conceptual question by using pausing and pacing. The question is conceptual question as the teacher was asking about the preposition of 
Siwalankerto street. The teacher gave a moment of silent to give time for the student to find the answer. It can be seen through (...).

\section{Empirical questions}

- Structuring:

(1.2.2) T: about a phone call, right? So now we are going to learn about how to speak on the phone and also talking about how to take message from someone. Now, I'm not crazy about this lesson, just to say that not really excited and I'm sure that this is not challenging for you. For one thing, we don't use telephone anymore, right? Back when I was a kid we had a house phone, right? Who of you that has house phone? Maybe some of you still have it and maybe some of not, but house phone are kind of up sleek, do you know that word? They no longer have a purpose because now everyone has their phone wherever they go, right? Usually, it is kind of pointless to have a phone in your house. Back when I was a kid we had a house phone, no we do not have cell phone back then long time ago. My first cell phone was, I bought it in 2001, that is my first cell phone but when I was a kid we had a house phone and when the phone ring somebody has to answer it, either my dad or my mom, my sisters or me, okay. If I am answering the phone and someone is asking for my dad, I need to have to call my dad, that is for you and if he is not there, I have to leave a message. Have you ever done this?

(S1.2.2) S: yes

Example above is the example of the teacher asking empirical question by using structuring tactic. This question is empirical question because this question helped the student to recall fact and observation from the student about a couple years back when phone was just discovered and how people used the phone back then. The teacher used structuring as the tactic because it contained a brief exposition of the topic by using his own experience and aimed to build on student previous knowledge and to add new knowledge.

- Directing and distributing:

(1.2.55) T: okay, do you thing you can spend that? Okay then thank you. Next

I need Aretta and Angel. Are you finish practicing you phone call? One more and we will continue. Okay Aretta, what do you want to buy?

(S1.2.64) S: a new camera

Example above is the example of the teacher asking empirical question by using directing and distributing tactic. This question is empirical question because the students need to make reasoning about why the students want to buy that gift and why that gift for that spesific student. The teacher is directing and distributing this question to one spesific student which is Aretta.

- Pausing and pacing:

(1.1.43) T: where can I get my camera repaired. Don't be afraid to improvise,

Improvise with your questions to say something like "my camera is broken, do you know where I can get it repaired?" okay? You can make up your own situation, I think that is helpful for you not to just read the script but to improvise, use your own thought and words, okay? So, student a are going to ask these six things, student b you are going to answer, find the place on the map where your partner needs to go and tell them okay? My camera is broken where can I get it repaired, what would be your answer?...

(S1.1.56) S: you could go to Ken Camera

Example above is the example of the teacher asking empirical question by using pausing and pacing. This question is empirical question because the students required observing the map and making possible experiment as which direction was the best way to get to camera repaired shop. The teacher gave a moment of silence (pausing) to give time for the student to answer his question because the answer was not yes or no question but a direction that needed couple of second time to see the answer on the map.

Moreover, the writer found out that in active class, for conceptual question, the teacher used pitching and putting clearly for 6 times, prompting and probing for 3 times, and directing and distributing for 2 times. On the other hand, for empirical question, the teacher used prompting and probing for 60 times, sequencing for 45 times, structuring for 11 times, listening to replies for 9 times, and directing and distributing for 5 times. In asking conceptual question, the teacher did not use structuring, pausing and pacing, listening to replies, and sequencing. On the other hand, in asking empirical question, the teacher did not use pitching and putting clearly. The result showed that in asking conceptual question, the teacher mostly used pitching and putting clearly tactic and the teacher 
mostly used prompting and probing tactic in asking empirical question. In asking conceptual and empirical questions, the teacher rarely used directing and distributing. The examples and the explanations are provided below.

\section{Conceptual questions}

- Pitching and putting clearly:

(2.2.143) T: not yet? Maybe next year. So next year you are a part of the committee, you can call the director or the head of the committee. You are going to ask these questions. Are there any event this week, yes there is a weekend trip on pad log dinner. Do you know what pot luck dinner is? What is pot luck dinner?

(S2.2.151) S: it is a dinner where we come to eat together

Example above is the example of the teacher asking conceptual question by using pitching and putting clearly. The question is conceptual meaning as the question is related to the meaning of "pot luck." The teacher used pitching and putting clearly as the tactic seeing that the tactic related to language register and knew whether the students were able to use technical terms or not.

- Directing and distributing:

(2.2.17) T: the gift and the person you want to buy it for, right? So I'm gonna ask you about that. Maybe about where is the best place to buy that gift, try remember what you talk about and where, especially if you are not from Surabaya, wehre your friends told you to go in Surabaya to buy that thing, okay. So I'm gonna ask you to come up here and I will give you score alright? This is part of your weekly participation score. So I'll give you score based on how you speak and we would do this, not in all class period, I'll come you to sit with me, that way I can hear you better and I could also correct you if there is something for you need to be corrected. Alright, we'll do that, just because I am talking with aomeone up here doesn't mean that you can do whatever you want. Do that activity part in the book like what I said before, don't just read the book read the words, put your thoughts and idea into tthis conversation and turns it to something funny. how you answer your phone? What would you say in Bahasa Indonesia?

(S2.2.32) S: halo

Example above is the example of the teacher asking conceptual question by using directing and distributing as the tactic. This question is conceptual question because the question asked about the concept of greetings in Bahasa Indonesia. The teacher was directing and distributing the question to all students in the classroom without specifically directing it to one student.

- Prompting and probing:

(2.1.70) T: pass B building, right? A B C, but also if I am standing on building

A and where is B building? You might say, oh! It is that way just before $\mathrm{C}$ building, right? So you can use this preposition and you need to think where you standing and say it every time. In this case you are standing here and the king building is just pass the park or after the park, so here are some preposition that you can use pass, after, before, across from, near, next to, what else?

(S2.1.88) S: beside

Example above is the example of the teacher asking conceptual question by using prompting and probing tactic. This is conceptual question because the teacher asked the concept of preposition that the students could use in giving direction. The teacher used prompting and probing as the tactic because the teacher wanted to receive some responses from the students about what other preposition that the students might have known other than those listed in the book.

The writer found three things that might affect what types and tactics of questions that the teacher used in class. First, the topic of the lesson might affect kinds of questions asked by the native speaker teacher. The topics of two meetings were direction and taking notes on a phone call; both topics did not contain any social, economy, or moral value. Therefore, the native speaker teacher did not ask any value question; he only asked conceptual and empirical types of questions.

Second, the situation of the class might affect what kinds of question and tactics that are asked by the native speaker teacher. In teaching active class, the teacher frequently used prompting and probing. Prompting and probing is a tactic that helped the teacher to get more answer and details from the students. In active class, the students were actively answering the teachers in big class situation. However, when the big classroom situation was changed into individual conference, the active student became quieter and answered the teacher's answer with short answers that were lack 
of details; therefore, the teacher used prompting and probing the most because he wanted to get more details from the students.

Third, the students' responses might affect kinds of question and tactics used by the native speaker teacher. In passive class, the teacher frequently used sequencing as the tactic of questioning. Sequencing is a tactic where the teacher asked questions at the same cognitive level. The teacher frequently used this tactic because when the teacher asked questions, frequently only one student and sometimes two students answered him. The teacher assumed that his questions were too difficult that caused only one student answering him. Therefore, he asked a lot of questions at the same cognitive level so the other students could give contributions or response.

\section{CONCLUSION}

The writer concluded 3 things. First, topic of the lesson might affect what types and tactics of questioning that the teacher used. Second, the situation of the class might affect how the teacher used types and tactics of questioning, in this case, when the teacher changed a big classroom into individual conference, the tactics of questioning that the teacher used are changed. Third, students' responses might affect what types of questions and what tactics of questioning that the teacher used.

\section{REFERENCES}

Arslan, M. (2006). The Role of Questioning in the Classroom. Dergi Park Academic, pp.81-103.

Creswell, J.W. (2001). Research Design: Qualitative, Quantitative and Mixed Methods Approaches. California: Sage.

Kayaoglu, M. N. (2013). Case Study into the Classroom Questions by a Native Speaker and a Non-Native Speaker Teacher in EFL Classes. Vol. 69.Asian EFL Journal. Ipp. 4-31.

Ma, X. (2008). The Skills of Teacher's Questioning in English Classes. International Education Studies, pp.92-100.

Medgyes, P. (2001). When the Teacher Is a Non-Native Speaker. In M. Celce-Murcia (Ed.), Teaching English as a second or foreign language. (3rd edition). Boston: Heinle \& Heinle, p.430.

Paulus, T., Lester, J. and Dempster, P. (2014). Transcribing Audio and Video Data. California: Sage. Retrieved from: http://methods.sagepub.com/book/srmpromo/mslRJq/digital-tools-forqualitative-research/n6.xml

Parkinson, G., \& Drislane, R. (2011). Qualitative research. In Online dictionary of the social sciences. Retrieved from http://bitbucket.icaap.org/dict.pl

Wragg, E. C., \& Brown, G. (2001). In Questioning in the Secondary School. London: Routledge. 